\title{
Public Perception of Driverless Trains
}

\author{
Anna Fraszczyk $^{1} \cdot$ Philip Brown $^{1} \cdot$ Suyi Duan ${ }^{1}$
}

Received: 9 March 2015/Revised: 17 May 2015/Accepted: 26 May 2015/Published online: 1 September 2015

(c) The Author(s) 2015. This article is published with open access at Springerlink.com

\begin{abstract}
The global trend for rail automation is increasing but there are very few publications on public perception of the ongoing changes in the railways. In order to fill this gap and to better understand people's perception of driverless trains, the paper focuses on automation of metro systems with a particular interest in unattended train operation (UTO). A survey seeking a public opinion on UTO was conducted, and the results show that $93 \%$ of female and $72 \%$ of male respondents think that a "fake" driver room should be present on a driverless train. In terms of human error, a great majority of respondents expressed no worries about a train design or maintenance issues. However, staff communication, selected by $36 \%$ males and $43 \%$ females, and a technical failure, highlighted by $50 \%$ of males and $43 \%$ of females, were two issues that raised most safety concerns amongst the respondents. Other results related to passenger's safety, employment, advantages and limitations of the UTO, amongst other issues, are presented and discussed in the paper.
\end{abstract}

Keywords Metro - Automation - Driverless train . Attitudes

\section{Introduction}

There are 148 cities with metro systems around the world [15], and so far 32 of them adapted automated metro systems [14]. The global trend for automation is increasing

Anna Fraszczyk

anna.fraszczyk@newcastle.ac.uk

1 NewRail, Newcastle University, King's Gate, Newcastle upon Tyne NE1 7RU, UK

Editor: Baoming Han with eight new systems being introduced into full operation between 2011 and 2013 [14]. Although the driverless technology is progressing quickly, public perception of unattended train operation (UTO) has not been researched much. With more UTO systems planned for operation by 2025, mainly in Australia, Asia and South America, this paper aims to highlight public perception of driverless trains, which, if taken into account, might help with better understanding of passengers' perspective on UTO and contribute to seamless implementations of the new systems around the globe.

A metro system, or a rapid transit system, is an urban transport system, which uses exclusive rails to run trains of high capacity without interruptions or contact with other transport systems or modes of transport [5]. Metro systems often involve some level of automation, from the most basic automatic train protection (e.g. automatic brakes application) to fully automated and driverless trains (e.g. Dubai Metro). There are four grades of train automation and the highest, with no staff on board, is referred to as UTO [14].

According to Karvonen et al. [7], there are three main reasons for automated train operation (ATO): cost effectiveness, high traffic frequency and flexibility. Moreover, these reasons are accompanied by a number of other advantages, such as punctuality and efficiency, which are widely highlighted by UTO enthusiasts (e.g. Observatory of Automated Metros). However, the UTO has a strong opposition in worker's unions and automation sceptics, who stress the safety issues of driverless trains and the drivers' loss of jobs [1].

Malla [8] argues that from a technical perspective, the debate on UTO having an advantage over conventional rail system is "almost over". However, from a passengers' perspective, the debate on advantages and disadvantages of 
UTO continues and is often based on people's perception of driverless trains, in terms of safety, rather than a reality [9]. This paper contributes to the debate by presenting results of a survey on public attitudes to and perceptions of driverless trains. A better understanding of this humansystem interaction is important in order to facilitate a smooth shift from conventional to automated metro systems, if this shift is going to happen on a greater scale in the future.

\section{History}

The debate on automated trains started over four decades ago when a number of publications on benefits of automated metro systems appeared. In 1973, Vuchic reviewed benefits of a driverless train, which included a high-frequency service and the flexible adjustment of train schedules [15]. Also in 1973, Berwell stated that "it is to be expected that the railway should be the first transport system to be automated" and listed a number of reasons for consideration [2]. The reasons, amongst others, included the same ownership and management of infrastructure and vehicles and the fact that automation was already in place with signalling or power control elements of the railway system, which would make a full train automation on a driverless train a natural step forward.

The first fully automated metro system was the SkyTrain introduced in Vancouver, Canada in 1985, which was originally built in time for Expo 1986. It is the oldest and one of the longest ATO systems in the world [10], with three lines and 47 stations in total. Since SkyTrain era, many other cities introduced automated metro systems with driverless technology with Everline in South Korea and Line 5 in Milan being amongst the most recent driverless systems implemented [14].

In 2013, there were 148 cities with metro systems around the world [14] and 32 of them used UTO [13]. The global trend for a full metro automation is increasing with eight new systems being introduced into full operation between 2011 and 2013 [13].

\section{Levels of Automation}

There are four grades of train automation (GoA), and Table 1, based on [12], explains the GoAs in more details. In general, the number of the grade depends on staff involvement in basic functions of train operation. The four main automated functions are setting train in motion, stopping train, door closure and operation in event of disruption. In the first grade, GoA1, a driver is involved in all four functions listed in Table 1, but his/her involvement is gradually reduced to zero in GoA4 where a train is fully automatic. The difference between GoA3 and GoA4 is that the first employs a train attendant, whereas the latter grade offers an unattended and fully ATO. UTO means that a rail vehicle runs fully automatically without a train driver or other operating staff onboard. It is a driverless train; however, some operators prefer to put a driver or a member of staff on board (e.g. Beijing Subway's Airport Express operates with a driver in a cab).

\section{Advantages of UTO}

UITP [12] argues that UTO (GOA4) brings many benefits to all key players in the system: passengers, train operators, funding bodies and staff. The key benefits of the driverless trains are [9, 12, 15] train running time optimisation, average speed of the system increase, headways shortening and dwell time in stations reduction, which all together translate into the first great benefit of UTO which is increased network capacity. Secondly, the UTO enthusiasts $[2,14,15]$ argue that by removing a driver from the train, the human-risk factor is reduced and overall safety and reliability of the system increases. Thirdly, in terms of operational costs of a driverless railway system, the

Table 1 The grades of train automation

\begin{tabular}{|c|c|c|c|c|c|c|}
\hline $\begin{array}{l}\text { Grade of automation } \\
\text { (GoA) }\end{array}$ & $\begin{array}{l}\text { Type of train } \\
\text { operation }\end{array}$ & $\begin{array}{l}\text { Setting train in } \\
\text { motion }\end{array}$ & $\begin{array}{l}\text { Stopping } \\
\text { train }\end{array}$ & $\begin{array}{l}\text { Door } \\
\text { closure }\end{array}$ & $\begin{array}{l}\text { Operation in event of } \\
\text { disruption }\end{array}$ & Example \\
\hline GoA 1 & ATP with driver & Driver & Driver & Driver & Driver & $\begin{array}{l}\text { London underground } \\
\text { Victoria line }\end{array}$ \\
\hline GoA 2 & $\begin{array}{l}\text { ATP and ATO with } \\
\text { driver }\end{array}$ & Automatic & Automatic & Driver & Driver & Paris Métro line 3 \\
\hline GoA 3 & DTO & Automatic & Automatic & $\begin{array}{l}\text { Train } \\
\text { attendant }\end{array}$ & Train attendant & $\begin{array}{l}\text { Airport express Beijing } \\
\text { subway }\end{array}$ \\
\hline GoA 4 & UTO & Automatic & Automatic & Automatic & Automatic & Dubai metro \\
\hline
\end{tabular}

$A T P$ automatic train protection, ATO automatic train operation, DTO driverless train operation, UTO unattended train operation

Source Based on [12] 
argument is that less train drivers equal cost savings [14], although more staff are recruited for other tasks. Fourthly, automated acceleration and deceleration patters help with energy recovery and savings contributing to environmentally friendly driving and cost savings [9]. Finally, from staff's perspective, drivers are no longer involved in monotonous tasks of driving a train, as their job profile changes, and they can be re-qualified and deployed along the line providing passengers with more customer service and staff-passenger interaction options [4, 14].

\section{Disadvantages of UTO}

Nevertheless the great number of advantages of UTO, the system has a number of disadvantages too when compared with a conventional system. Firstly, UTO requires a higher cost of implementation as it involves automation at the levels of rolling stock, signalling and platform [12]. Secondly, maintenance costs of the UTO system are higher as additional platform and track protection systems must be installed and maintained. Overall, the initial investment into UTO infrastructure and driverless vehicles is high [11].

Thirdly, from a human-system interaction perspective, as Karvonen et al. [7] argue, as the driver disappears from the train, the significant link between the passengers and the metro system becomes weaker or is lost. Karvonen et al. [7] studied Helsinki metro drivers' behaviour and identified 16 metro train drivers' sub-tasks (hidden roles), such as making announcements to the passengers, guiding passengers out, interpreting events in the environment or fixing small faults in exceptions. In the light of "hidden roles" of a driver, UTO might be a great disadvantage, especially in the case of emergencies happening in the field, as unattended train will no longer provide a driver in situ capable of fixing simple failures or informing the control centre about problems and current situation in the field [3]. Finally, UTO requires a highly qualified maintenance personnel in the field [15], but also in the control room, which leads to changes in driver's job profile and the need for new qualifications and training for staff. Rail trade unions around the globe are generally against UTO arguing that train automation raises safety concerns and causes job loses $[1,6,11]$.

\section{Methodology}

This study used a paper-based survey as a data collection method. Although other methods of data collection, such as focus group, interviews or observations, were also considered, the questionnaire method was selected as best for the project in terms of the shortest time scale needed for data collection and analysis and the lowest budget required.

\subsection{Questionnaire Design}

The questionnaire used in the study was designed by a Master student as part of her rail major project focused on passengers' perception of automatic trains. The questionnaire was divided into three parts, with the first and largest part being about attitudes to and perceptions of automated trains, the second requesting information about the respondent and the third part offering space for additional comments.

The questions included in the first part of the questionnaire could be divided into technical questions and questions of opinions and preferences, and examples of the questions are presented in Table 2.

The great majority of questions were of closed type and offered specific answers, and respondents were asked to mark one answer per question only. However, two openended questions were included as follow-up on reasons why people might be afraid of using driverless trains and opinions about driverless train technology in general. Overall, the survey included 21 questions on attitudes to and perceptions of driverless train technology and three personal questions asking for respondent's age, gender and country of origin.

\subsection{Data Collection}

The questionnaire was distributed in July 2014 and was answered by participants of a rail summer school, both students and professors. The student respondents included in the sample had some background knowledge on the complexity of the railway system before completing the

Table 2 Examples of questions and answers included in the survey

\begin{tabular}{|c|c|}
\hline Question of opinion and preference & Answer options given \\
\hline $\begin{array}{l}\text { What do you think about driverless train } \\
\text { technology? }\end{array}$ & $\begin{array}{l}\text { a. Very good } \\
\text { b. Good } \\
\text { c. Neutral } \\
\text { d. Bad } \\
\text { e. Very bad }\end{array}$ \\
\hline $\begin{array}{l}\text { How would you rate the importance of a } \\
\text { driver on a train? }\end{array}$ & $\begin{array}{l}\text { a. Very important } \\
\text { b. Important } \\
\text { c. Neutral } \\
\text { d. Not important } \\
\text { e. Not at all important, } \\
\text { not necessary }\end{array}$ \\
\hline $\begin{array}{l}\text { Do you think the driver room should be } \\
\text { built on driverless trains? }\end{array}$ & $\begin{array}{l}\text { a. Yes } \\
\text { b. No }\end{array}$ \\
\hline
\end{tabular}


questionnaire; however, driverless trains and metro automation topics were not included in the summer school's curriculum.

\section{Analysis of Results}

\subsection{Sample Size and Age}

The questionnaire was answered by 50 people from 10 countries (see Fig. 1 for details). The age range within the sample was from 17 to 62 with $75 \%$ under 30 years old, and a gender split was 36 men and 14 women. It is shown in Fig. 1 that majority of respondents represented six countries: Romania (8 respondents), Italy and the UK (7 respondents each), Portugal (6 respondents), Poland and Bulgaria (5 respondents each). Interestingly, Bulgaria was the only country with all respondents being females (no male Bulgarian students attended the summer school in 2014). The remaining four countries, namely Czech Republic, Turkey, China and Germany, had between two and four representatives within the sample.

\subsection{Preferred Type of a Train}

As the purpose of the survey was to investigate public perception of driverless trains, the respondents were asked for their preferred train when travelling and were given a choice of three answer options: "Driver train", "Driverless train" and "Any train", where the latter answer indicated no specific preference and could be interpreted in favour of driverless trains option.

The respondents were also asked whether they are worried about using a driverless train and were given three answer options: "Yes", "No" and "Not Sure". Responses to this question were combined with responses to the question on preferred type of train and both are presented in Fig. 2. The results displayed in Fig. 2 show that a great majority of the sample, up to $64 \%$ of all respondents (middle of the graph with "No" answer option), is not worried about using driverless trains. Moreover, the answers are at a similar level for both genders, and over half of males $(58 \%)$ and females $(57 \%)$ do not worry about using a driverless train and could use a driverless train or whatever train. Only $11 \%$ of males and $14 \%$ of
Fig. 1 Sample size and countries represented (count)

Fig. 2 Choice of a type of a train versus worry of using a driverless train $(\%)$
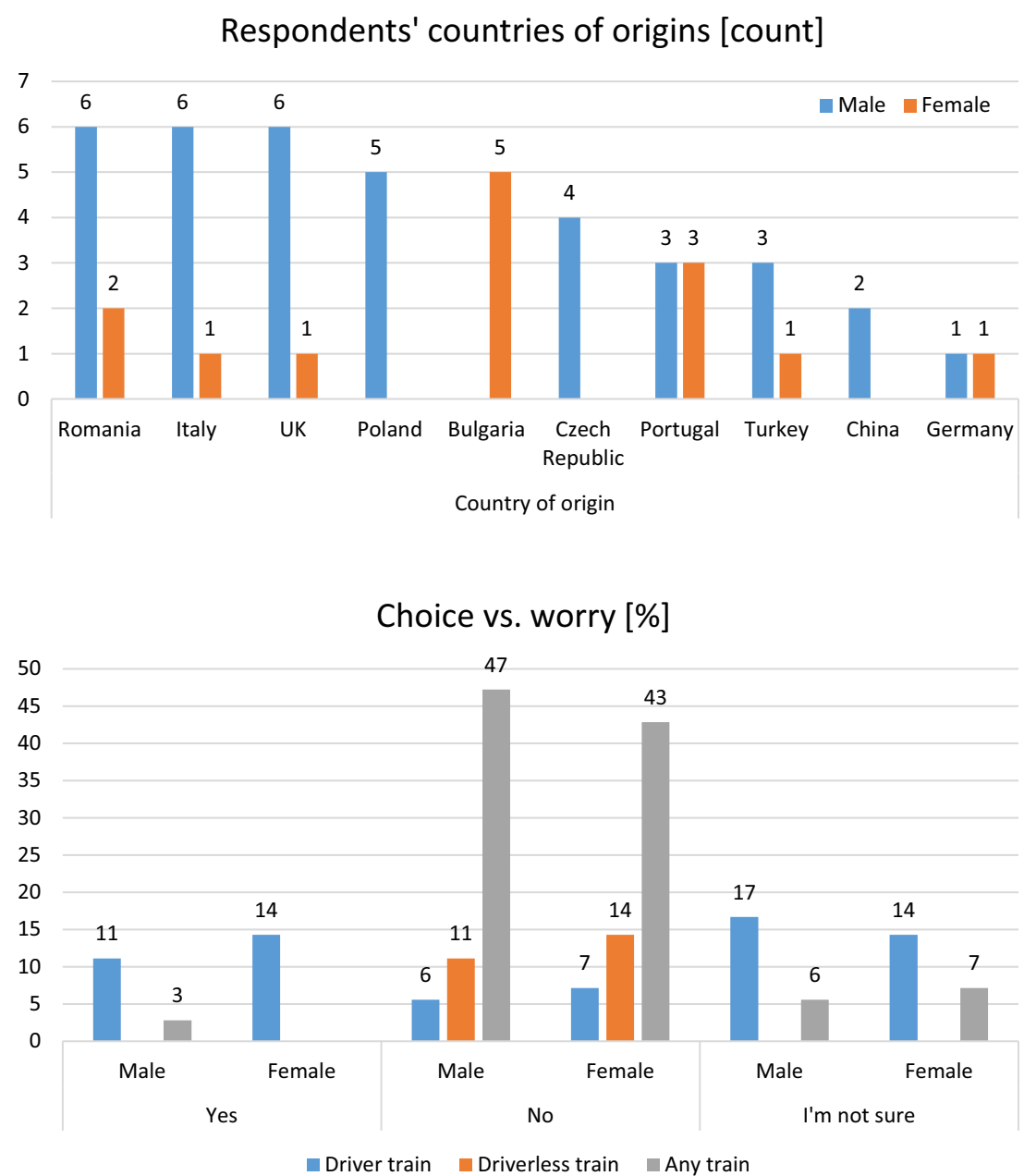
females are worried about using a driverless train and, if given a choice, would prefer to use a traditional train with a driver. This result shows that in general the respondents are not worried about being on a train without a driver and in fact nearly half of them is not event bothered about the train type ("Any train" option in Fig. 2).

\subsection{Driverless Train Technology}

Although more driverless trains are in operation worldwide and passengers are using them on a daily basis, peoples' opinions on the technology used on driverless trains are not publicised much. Therefore, the respondents have been asked to rate driverless train technology on a 5-point scale with "Very Good" being the highest rate and "Very Bad" being the lowest rate.

Figure 3 shows that $72 \%$ of males and $93 \%$ of females rated the driverless train technology as at least "Good". Although the majority of the sample is of a positive opinion, there are still $25 \%$ of males and $7 \%$ of females who are neutral and only $3 \%$ of males with a negative view on a driverless train technology.
Overall, $78 \%$ of the sample rated UTO as "Very Good" or "Good". Despite the fact that $34 \%$ of the sample would prefer a train with a driver, majority of the respondents within this group still rated driverless trains as "Very Good" $(4 \%)$ or "Good" $(16 \%)$. The driverless train enthusiasts were in minority and formed $12 \%$ of the sample only. Although none of the driverless train enthusiast rated this option negatively ("Bad" or "Very Bad"), the split between "Very Good" and "Good" was from $6 \%$ to $4 \%$. The largest group of respondents, $60 \%$ of the sample, selected "Any train" train as their preferred option showing that they could ride either a driver or a driverless train (Fig. 4).

\subsection{Factors Influencing Preferences}

According to UTO advocators, the driverless system brings a number of benefits to their users (see Sect. 4), mainly in terms of time and frequency of services. The respondents were asked to select reasons which would influence their preference for driverless train over a driver train. The list of options included reduced ticket price, extended running periods, increased train frequency and other.
Fig. 3 Respondents' opinions on driverless train technology (\%)

Fig. 4 Opinions on driverless trains versus choice of a type of a train $(\%)$

\section{What the respondents think about driverless train technology? [\%]}

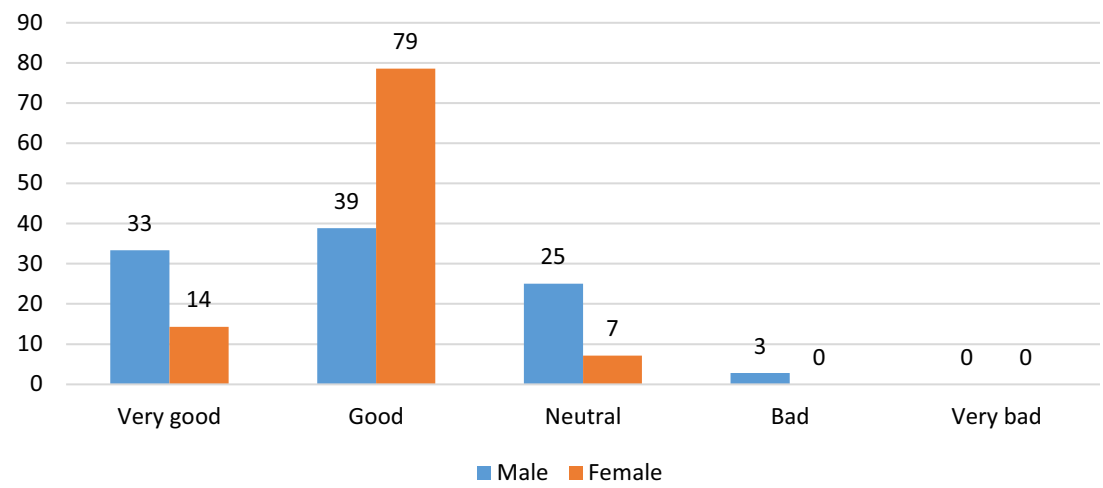

Opinions on driverless trains vs. preferred type of train

[\%]

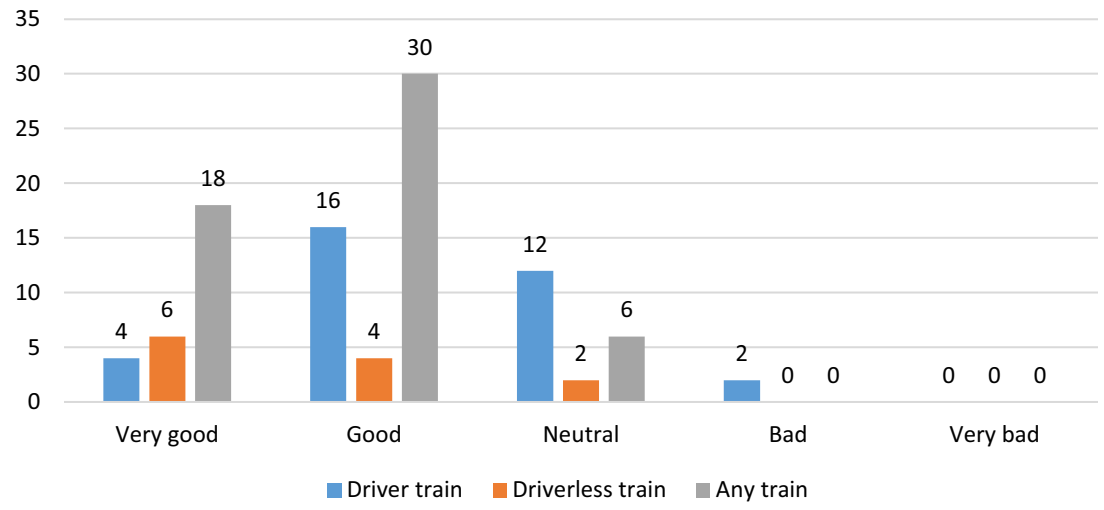


Results displayed in Fig. 5 show that none of the options given would convince the majority of respondents to choose a driverless train as a preferred option. However, based on the answers given, it can be seen that it would be more difficult to convince females to use driverless trains as over half of the female sample stated that none of the three factors presented in Fig. 5 would influence their choices. Although male responses were similar, the split between "Yes" and "No" answers for "extended running periods" and "increased train frequency" was more equal (47 \% for "Yes" vs. $53 \%$ for "No" and $50 \%$ for "Yes" vs. $50 \%$ for "No", respectively). The results suggest that perhaps new or other measures, to these presented in the survey, should be used when campaigning for change in public's perception of driverless trains and the benefits the UTO systems offers as the benefits listed in Fig. 5 did not get a great respondent's support.

\subsection{Importance of a Driver}

Although UTO is designed to be fully operational without a member of staff on board, some operators choose to put staff on board (e.g. Budapest Metro Line M4, Airport Express Beijing Subway), especially at the early stages of system's implementation. In this light, the respondents were asked about the importance of a driver on a train, but also about a need for a driver room on a driverless train. The latter is obviously a "fake" room, but in principle its purpose is to help with a shift from a driver to a driverless system and accommodate a smooth change in users' acceptance of the new system.

Both male and female respondents agree that a driver room should be present on a driverless train; however, the issue seems to be much more important to females (93\% of females) than males (72\% of males). Moreover, majority of females who would like to see a driver room on a driverless train rated the presence of a driver on a train as "Very Important" or "Important" (14 and $50 \%$, respectively). This result shows that females within the sample are much more than males attached to the idea of a driver on a train as well as more comfortable with a train with a driver room installed. The gender differences in the responses presented in Fig. 6 highlight the fact that how
Fig. 5 Factors that would influence a driverless train as a preferred option $(\%)$

Fig. 6 Importance of a train driver versus a need for a driver room on a driverless train (\%)

\section{Factors that would incluence a driverless train as preferred option [\%]}

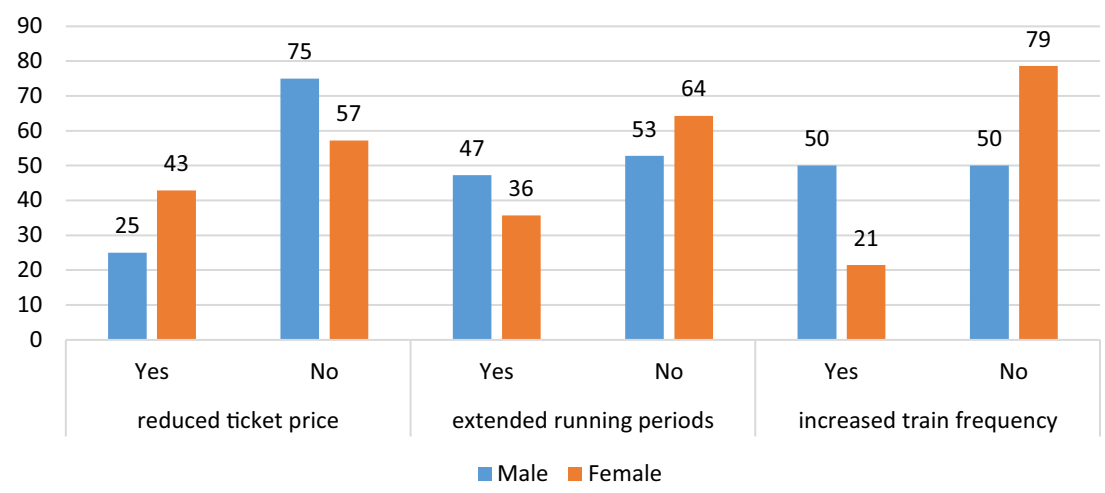

Importance of a driver vs. driver room [\%]

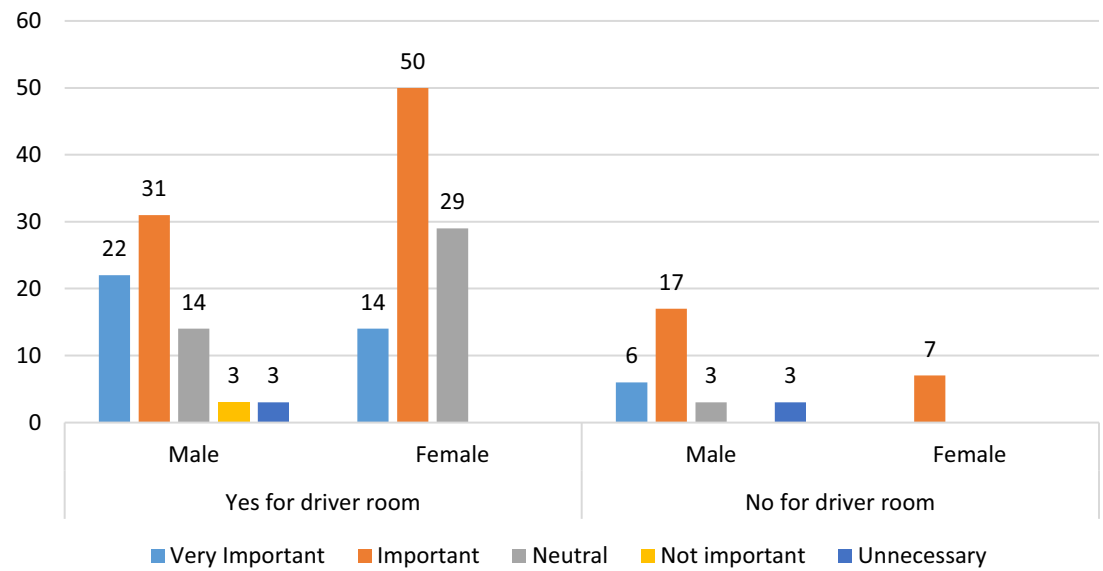


both genders see the role of a driver on a train, and this issue requires further investigation as it can potentially lead to other issues and identification of other explanatory variables.

\subsection{Human Error}

Although UTO enthusiasts highlight the advantage of the automated systems where a human error is reduced or eliminated, the fact is that people, from train designers to control room staff, are still involved in the UTO system. The respondents therefore have been asked to select areas where, according to their opinion, a human error is likely to occur.

Results displayed in Fig. 7 show that a great majority of respondents expressed no worries about a train design or maintenance issues (only $11 \%$ of males and $28 \%$ of males versus $14 \%$ of females, respectively). However, a communication between staff boosted the level of worried respondents to $36 \%$ amongst males and $43 \%$ amongst females. The results suggest that respondents see a staff communication as an area where human error is more likely to occur than in a design or a maintenance domain. Moreover, $50 \%$ of males and $43 \%$ of females were worried about a technical failure of UTO and, although this is only half of the sample or less, this issue strikes as an area of greatest concern amongst the respondents out of the four areas listed on Fig. 7.

\subsection{Unemployment Issue}

The position of train drivers' trade unions campaigning against driverless trains is well known as well as their argument of drivers losing jobs and contributing to higher unemployment rates. However, opinions of the public on this issue are unknown. Thus the respondents were asked about their opinions on unemployment increase connected to driverless trains' implementations. Figure 8 displays clearly that $62 \%$ of the respondents are not worried about drivers losing their jobs as they believe that the drivers could requalify and do other jobs. However, $36 \%$ of the respondents agree that the unemployment rates will increase with implementations of driverless trains.

\section{Conclusions}

Although automated and driverless trains have been in operation for over three decades, there has not been many scientific research work published on public attitudes to and perceptions of UTO.

In order to contribute to a better understanding of people's perception of driverless trains, this paper presented results of a survey where 50 individuals were asked about their opinions on UTO. Although it might be argued that the sample was biased because all respondents were somehow interested in the railways, it must be highlighted
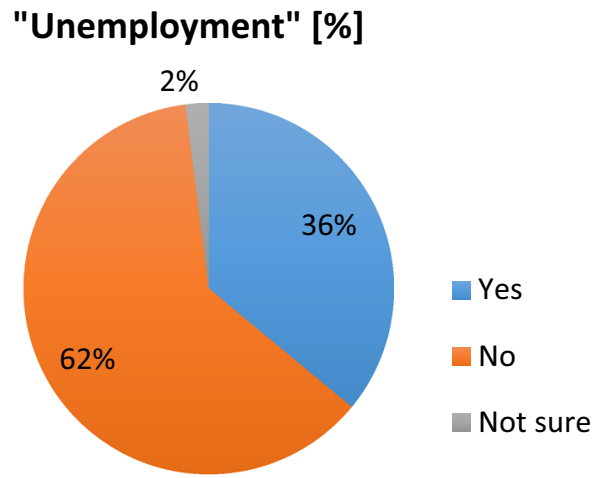

Fig. 8 Will implementations of driverless trains contribute to increase of drivers' unemployment? $(\%)$
Fig. 7 Areas of human error in an UTO system (\%)

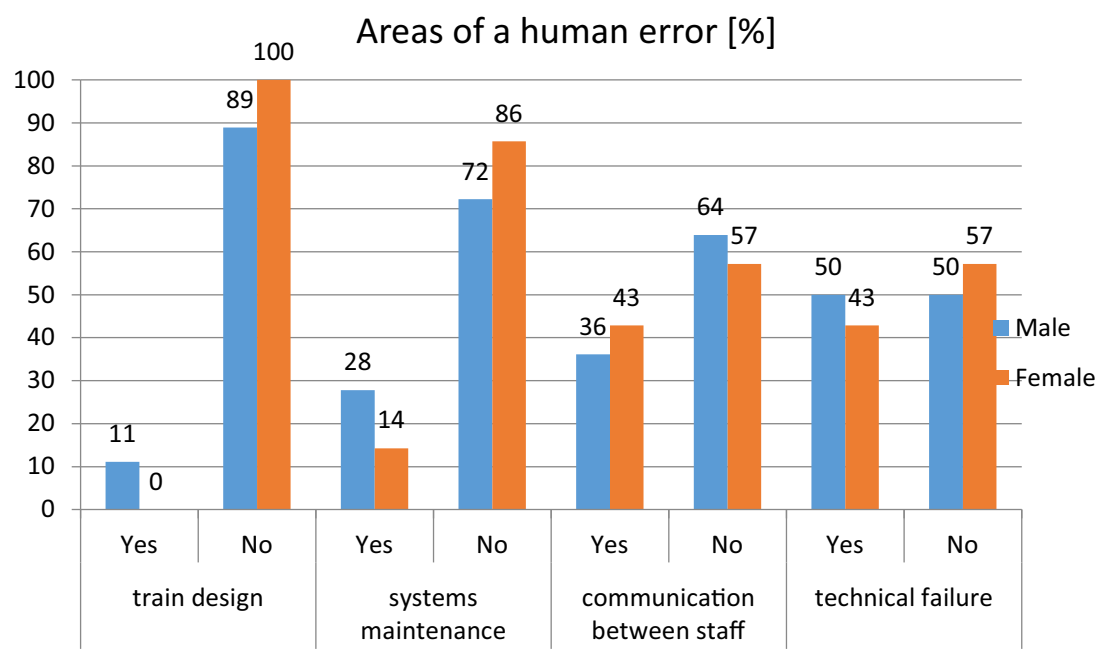


that they are also passengers with personal opinions about the railway system and the survey sought their individual opinions on UTO.

The results presented in the paper can be grouped into three thematic areas: train type preferences and opinions on driverless trains, importance of a driver on a train and the unemployment issues and a human error issue.

Firstly, only $11 \%$ of males and $14 \%$ of females stated that they would prefer to use a traditional train with a driver rather than a driverless train or whatever train. This result shows that the majority of the respondents is not bothered about the train type they are using. Moreover, opinions about the driverless technology are very positive and rated as a "Very Good" or "Good" technology by the overwhelming majority of $93 \%$ females and $72 \%$ of males within the sample. This shows that in general the respondents are keen on UTO and they do not have a problem to trust the technology.

Secondly, the importance of a driver on a train was rated as "Important" or "Very Important" by the majority of the respondents who highlight the perception of a driver as an important component of the system. Moreover, over $50 \%$ of the sample agreed that there should be a driver's room on the train, which in the case of a driverless technology is obviously not necessary.

Thirdly, despite many drivers' trade unions campaigning against driverless trains, the results presented in the paper show that the majority of respondents $(62 \%)$ do not see the implementation of UTO as a thread to a driver's job security. However, as there was no follow-up of the unemployment question, it is difficult to understand respondents' reasons for being "for" or "against" the idea that driverless trains will affect train drivers' employment.

Fourthly, the results revealed that the respondents overall are not worried about human error occurring on a driverless train. However, when looked into more detail, it appears that a technical failure and a staff communication issues are the two main areas of concern in relation to a human error on UTO.

\section{Further Research}

Overall, this paper contributes to the discussion on driverless trains but much more research needs to be done to fully understand and monitor public perceptions of and attitudes to UTO. This knowledge could be a powerful tool used in the future campaigns promoting driverless trains and could have a role to play in seamless implementations of the new systems around the globe.

More specifically, a more detailed investigation of public level of understanding of technology behind UTO might help to examine the reasons why although respondents trust the technology they do not specifically go for it if given a choice between a driver train and a driverless train.

Next, the public perception of the role of a driver on a driverless train requires further investigation where links with issues such as safety and security and anti-social behaviour on a train could be explored.

To follow-up the employment issue, a further investigation into the reasons why the public perceives chances of the drivers to requalify and stay on the job quite high would be needed to better understand their motivations which could be used in the future promotion of the driverless trains to drivers' trade unions and the public.

Finally, in order to further investigate public opinions of areas where they fear a human error might occur, a more detailed study of perceptions and preferences on UTO would be needed. This could help to design public campaigns explaining how UTO system works and enforce technical strategies for overcoming the possibility of a human error to occur on UTO system.

Acknowledgments This paper is based on results collected by an MSc student Suyi Duan who investigated passengers' perception of driverless trains as part of her major project at the School of Mechanical and Systems Engineering at Newcastle University. Philip Brown, a college student on Nuffield Research Placements at Newcastle University, contributed to the analysis of results of the project.

Open Access This article is distributed under the terms of the Creative Commons Attribution 4.0 International License (http://crea tivecommons.org/licenses/by/4.0/), which permits unrestricted use, distribution, and reproduction in any medium, provided you give appropriate credit to the original author(s) and the source, provide a link to the Creative Commons license, and indicate if changes were made.

\section{References}

1. BBC (2014) Driverless tube trains: Unions vow 'war' over plan. http://www.bbc.co.uk/news/uk-england-london-26381175. Accessed 9 Dec 2014

2. Berwell FT (1973) Automatic railways: automation and control in transport. Pergamon Press, Oxford, pp 177-191

3. Brown P (2014) Are driverless trains the future? Rail Technology Magazine, February/March 2014, p 19

4. Fisher E (2011) Justifying automation. In: Railway technology. http://www.railway-technology.com. Accessed 5 Dec 2014

5. Fraszczyk A, Magalhães da Silva J, Gwóźdź A, Vasileva G (2014) Metro as an example of an urban rail system. Four case studies from Europe. Transp Probl 9:101-107

6. Hasham N (2013) Driverless trains plan must overcome public scepticism. http://www.smh.com.au/nsw/driverless-trains-planmust-overcome-public-scepticism-20130607-2nvjq.html. Accessed 9 Dec 2014

7. Karvonen H, Aaltonen I, Wahlström M, Salo L, Savioja P, Norros L (2011) Hidden roles of the train driver: a challenge for metro automation. Interact Comput 23:289-298

8. Malla R (2014) Automation sets a new benchmark. Metro report, May 2014 
9. Rumsey A (2009) Communications based train control. IRSE seminar

10. TransLink (2014) SkyTrain. http://www.translink.ca/en/Schedulesand-Maps/SkyTrain.aspx. Accessed 9 Dec 2014

11. UIC (2014) Automatic train control. Energy efficiency technologies for railways. http://www.railway-energy.org/static/Auto matic_train_control_79.php. Accessed 9 Dec 2014
12. UITP (2011) Media backgrounder. Metro automation facts, figures and trends. UITP, Brussels

13. UITP (2013) Metro automation in 2013. Observatory of Automated Metros World Atlas Report. UITP, Brussels

14. UITP (2014) Statistics brief. World metro figure. UITP, Brussels

15. Vuchic V (2014) Maintaining performance with full automation. Metro report international, March 2014, pp 36-39 